\title{
Towards a Coupled Environmental Prediction System
}

\author{
Julie L McClean ${ }^{1}$, Wieslaw Maslowski ${ }^{1}$, and Mathew Maltrud ${ }^{2}$ \\ ${ }^{1}$ Department of Oceanography, Naval Postgraduate School, Monterey, California, USA \\ mcclean@nps.navy.mil, maslowsk@nps.navy.mil \\ ${ }^{2}$ Los Alamos National Laboratory, Los Alamos, New Mexico, USA \\ maltrud@lanl.gov
}

\begin{abstract}
Towards the realization of a global coupled air/ocean/ice predictive system for Navy needs, two high resolution modeling efforts are underway whose goals are the development and upgrading of the ocean and sea ice components. A $0.1^{\circ}$, 40-level global configuration of the Los Alamos National Laboratory (LANL) Parallel Ocean Program (POP) integration is being performed on an IBM SP3; this is the first time an ocean simulation of this size has been carried out. The Polar Ice Prediction System (PIPS) 3.0 uses a $1 / 12^{\circ}, 45-$ level grid and covers all the northern ice-covered regions. The latter model and a $0.1^{\circ}, 40$-level North Atlantic only POP integration are compared with coarser resolution runs and observations, demonstrating the importance of high resolution to the representation of ocean circulation. Mean volume and heat transports into the Arctic are realistically simulated by PIPS 3.0.
\end{abstract}

\section{Introduction}

State-of-the-art super-computer technologies are providing the US Navy with the means to progress towards the realization of their vision of a high resolution operational global air/ocean/ice system for the prediction of environmental conditions. An understanding of the atmosphere-ice-ocean states and their variability in the form of short-term predictions of weather, ocean, and ice conditions are important to daily Naval operations and critical in the battlespace environment. Part of the modernization effort in the Navy involves the development of improved codes for ocean and sea ice simulations, which employ the best representations of sub-grid scale physical processes while taking advantage of available computer resources.

Two parallel efforts are underway that are making progress towards these goals by developing and upgrading the ocean and sea ice components of this future coupled Navy environmental prediction system. The spin-up of a global $1 / 10^{\circ}, 40$-level ocean model is underway; upon completion it will be delivered to the Fleet Numerical Me- 
teorological and Oceanographic Center (FNMOC) for testing and transition to the operational environment. The Polar Ice Prediction System (PIPS) 3.0, which will replace PIPS 2.0 providing forecasts of ice conditions in the Northern Hemisphere, uses a $1 / 12^{\circ}, 45$-level grid and covers the northern ice-covered oceans. It is currently being transitioned for operational use.

The ocean model being used in both the global and PIPS prediction systems is the Los Alamos National Laboratory (LANL) Parallel Ocean Program (POP) model. It is a primitive equation z-level model with a free-surface boundary condition. Approximations to the governing fluid dynamics equations permit a decoupling of the model solution into barotropic (vertically averaged) and baroclinic (deviations from vertically averaged) components; these are solved using an implicit elliptic scheme and an explicit parabolic equation system, respectively. It is written in Fortran90 and was designed to run on multi-processor machines using domain decomposition in latitude and longitude. MPI is used for inter-processor communications on distributed memory machines and SHMEM on shared memory machines. Further technical details and references regarding the code and its adaptation for massively parallel computers can be obtained from http://climate.acl.lanl.gov. The sea ice model in PIPS3.0 is configured on the same grid as the ocean model. A system of ice model equations is solved as a set of coupled, initial/boundary value problems using a staggered Arakawa-B gird. Details of numerical approach in this model can be found in Bitz (2000).

Benchmarking shows POP to be highly scalable onto a large number of processors provided the processor sub-grid is large enough (Figure 1). Timings of a flat-bottom test case where the number of grid points correspond to the sizes of global grids with horizontal resolutions of $0.1^{\circ}, 0.2^{\circ}$, and $0.4^{\circ}$, and 40 vertical levels were made on an IBM SP3 (Navy Oceanographic Office) using 160, 320, 500, and 600 processors. The barotropic mode is less scalable at lower resolutions and higher number of processors. In the $0.4^{\circ}$ case the barotropic mode dominates the total run-time for all but the smallest number of processors. This is caused by too much time being spend in communication among nodes relative to that in calculation on each node. To improve performance of the barotropic model and to increase on-node performance by a factor of two numerical improvements are underway using an OpenMP/MPI hybrid scheme.

Any ocean model to be used in these coupled prediction systems must be capable of producing spatial scales between 10 and $1000 \mathrm{~km}$ and temporal scales up to several months. One of the challenges facing us therefore, has been the trade-off between adequate model resolution and the availability of computing resources. Through a Department of Defense (DOD) High Performance Computing Modernization Office (HPCMO) Grand Challenge Grant, we have been able to perform these very realistic simulations that hitherto have not been possible. Results presented here reflect these 


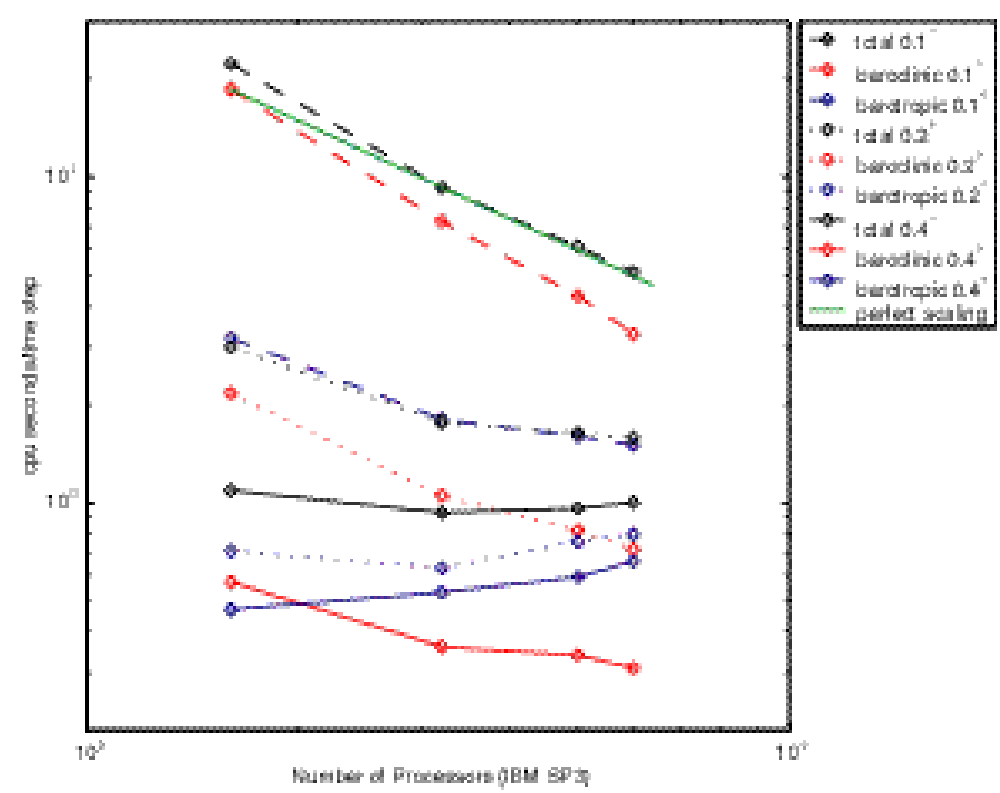

Fig. 1. Total (black), baroclinic(red), and barotropic (blue) timings (wall clock time per time step) on a log-log scale of global POP with horizontal resolutions of $0.1^{\circ}, 0.2^{\circ}$, and $0.4^{\circ}$, and 40 vertical levels on an IBM SP3.

challenges and concentrate on improvements from high resolution and added physics.

\section{A High-Resolution Global Ocean POP simulation}

Ocean models used for Navy prediction purposes must be able to realistically reproduce the statistical nature of the surface circulation. Prior to committing to a chosen resolution for the global simulation, quantitative measures of the realism of this flow were calculated from two Mercator configurations of POP: a recent $0.1^{\circ}$, 40 -level North Atlantic only simulation and a $0.28^{\circ}$, 20-level near-global case run several years ago at LANL (Maltrud et al., 1998). If the statistics from the higher resolution POP were only slightly more realistic than those from the coarser run, then large computational savings can be made using lower resolution. Both models were forced with daily winds and monthly climatological heat fluxes. An explicit mixed-layer formulation, K-profile Parameterization (KPP), was active in the North Atlantic POP.

The evaluations of the ocean models were performed using the North Atlantic 
surface drifter data set for the years 1993-1997; the spatial and temporal coverage of these drifters is extensive, providing an excellent database from which to calculate statistics of the surface circulation. The drifter tracks and the numerical trajectories from the $0.28^{\circ}$ and $0.1^{\circ}$ POP runs from 1995 and 1996 are seen in Figures 2a, b, and c, respectively; two years only are plotted so that details can be seen clearly. Specifics of the realism of these surface trajectories are discussed further in McClean et al. (2001). Here, it is sufficient to state that the coverage of the domain by the $0.28^{\circ}$ POP trajectories displays many gaps and is not uniform, unlike the observations. Also many of the trajectories preferentially follow coherent flows. The coverage by the $0.1^{\circ}$ trajectories is much more extensive arising from the increased mesoscale eddy activity in the higher resolution model. Additionally, the pathways and structure of the currents are more faithfully represented in the higher resolution case. Quantitative calculations supported these qualitative findings. Eulerian results showed that flow features in the coarser run were unrealistic or misplaced and the variability was underrepresented relative to the observations; in the $0.1^{\circ}$ POP the variability and current structures were much more realistically simulated. The intrinsic Lagrangian (trajectory-based) scales from the $0.1^{\circ} \mathrm{POP}$ were not statistically different from the observed quantities, while those from the $0.28^{\circ}$ model did differ.

Based on these and other results (Bryan et al., 1998), it was decided that a global simulation to be used for synoptic forecasting would require horizontal and vertical resolutions of at least $0.1^{\circ}$ and 40 vertical levels, respectively. Such a simulation is underway using 500 processors on the IBM SP3 at the Navy Oceanographic Office. The model uses a displaced pole grid whereby the North Pole is rotated into Hudson Bay avoiding the issue of the polar singularity. The grid consists of $3600 \times 2400 \times 40$ grid points with $0.1^{\circ}$ at the equator. A blended bathymetry was created from Sandwell and Smith (1997, http://topex.ucsd.edu/marine_topo), International Bathymetric Chart of the Arctic Ocean (IBCAO, Jakobsson et al., 2000), and British Antarctic Survey (BEDMAP, http://www.antarctica.ac.uk/bedmap) products. The model was initialized using the Navy's MODAS $1 / 8^{\circ}$ January climatology outside of the Arctic and the University of Washington's Polar Hydrography winter climatology in the Arctic (http://psc.apl.washington.edu/Climatology.html). Surface momentum, heat, and salinity fluxes were calculated using bulk formulae based on the model surface temperature and an atmospheric state comprised of daily and monthly data from a variety of sources (as in Large et al., 1997). These fluxes are used to force the model during the current twenty-year spin-up. The KPP mixed layer formulation is active.

Figure 3 shows sea surface temperature and sea surface height fields from the Atlantic and Indian Oceans, respectively, at the end of the first year of the spin-up. Gulf Stream and equatorial fronts are clearly seen in the Atlantic and mesoscale activity 
1102 J.L. McClean, W. Maslowski, and M. Maltrud
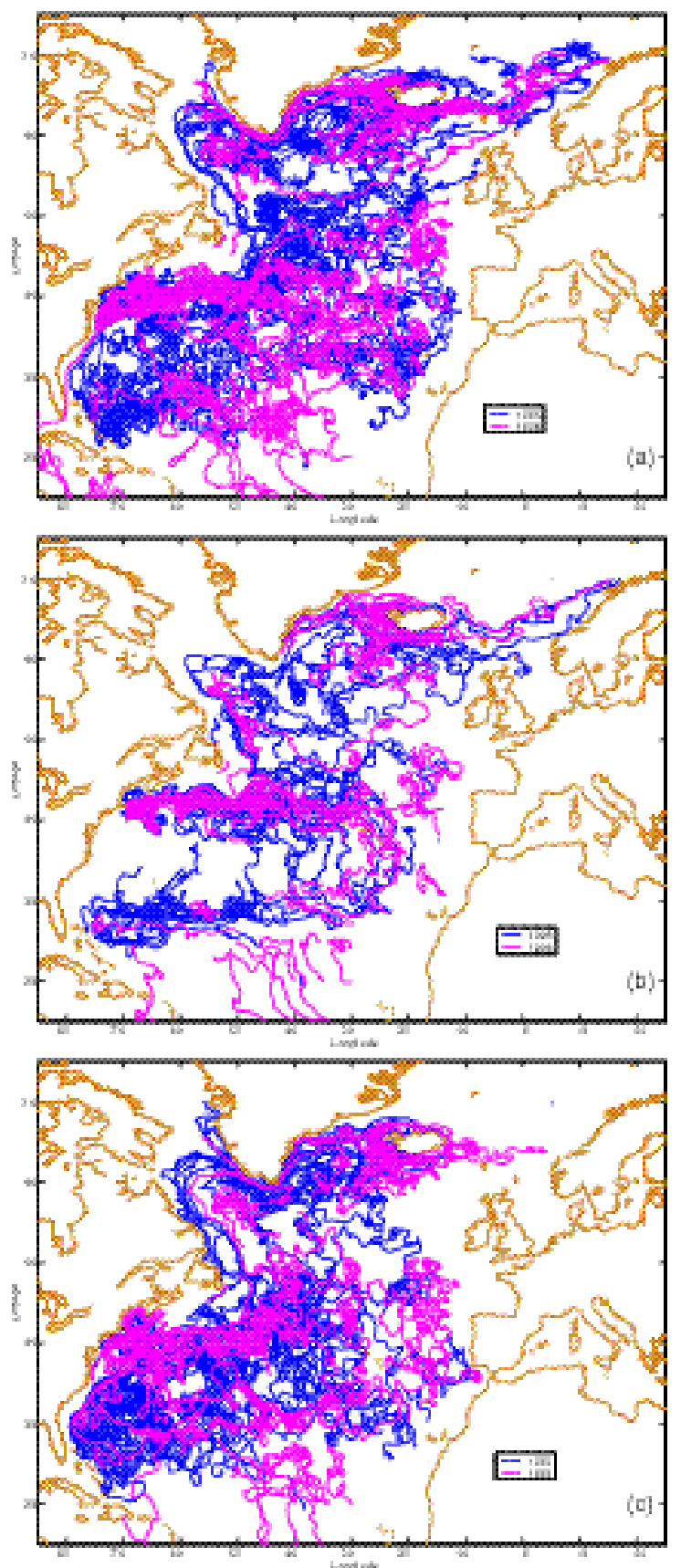

Fig. 2. North Atlantic (a) surface drifter tracks, (b) $0.28^{\circ}$, and (c) $0.1^{\circ}$ POP numerical trajectories for 1995-1996 


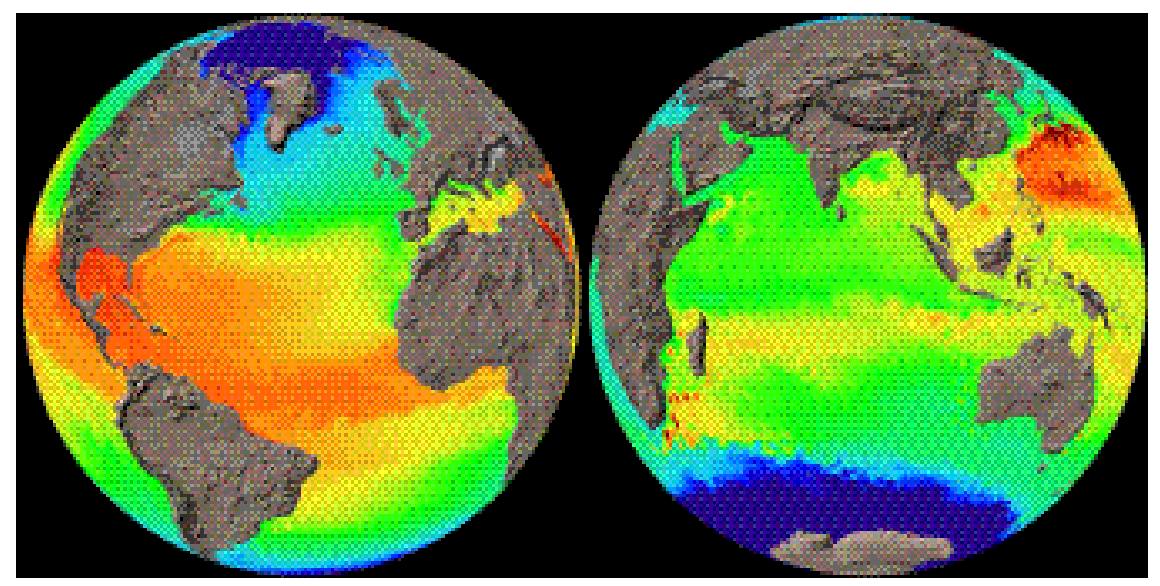

Fig. 3. Snapshots of sea surface temperature and sea surface height in the Atlantic and Indian Oceans, respectively, from the $0.1^{\circ}$ global POP integration.

associated with the Agulhas Current offshore of east Africa is apparent. The separation of the Kuroshio off Japan is also observed. Output from the spin-up is being monitored to watch the set-up of the major currents, the impact of outflows on the thermohaline circulation, and the development of water masses. Following the spinup, the model will be forced with realistic Navy surface forcing for the better part of a decade for the purposes of understanding features and processes important to the Navy in many different parts of the globe.

\section{PIPS 3.0 Model Description and Results}

The PIPS 3.0 model is configured on a $1 / 12^{\circ}(\sim 9 \mathrm{~km})$ rotated spherical coordinate grid. The model domain (Figure 4) extends from the North Pacific at $\sim 30^{\circ} \mathrm{N}$, through the Arctic Ocean into the North Atlantic to $\sim 40^{\circ} \mathrm{N}$. The model bathymetry incorporates the $2.5-\mathrm{km}$ resolution IBCAO digital bathymetry data set. It is represented by 45 $\mathrm{z}$-coordinate levels. The model is considered to be eddy-permitting as features down to $40-50 \mathrm{~km}$ can be resolved. With the radius of deformation in the Arctic Ocean approaching $10 \mathrm{~km}$, many of the smaller features are still not properly accounted for. The high resolution combined with the pan-Arctic domain allows the representation of most of the important processes in the Arctic Ocean and realistic exchanges between the North Pacific, the Arctic Ocean, and the North Atlantic.

The sea ice model at present uses viscous-plastic rheology and the zero-layer approximation of heat conduction through ice. The ongoing upgrade of this model inclu- 


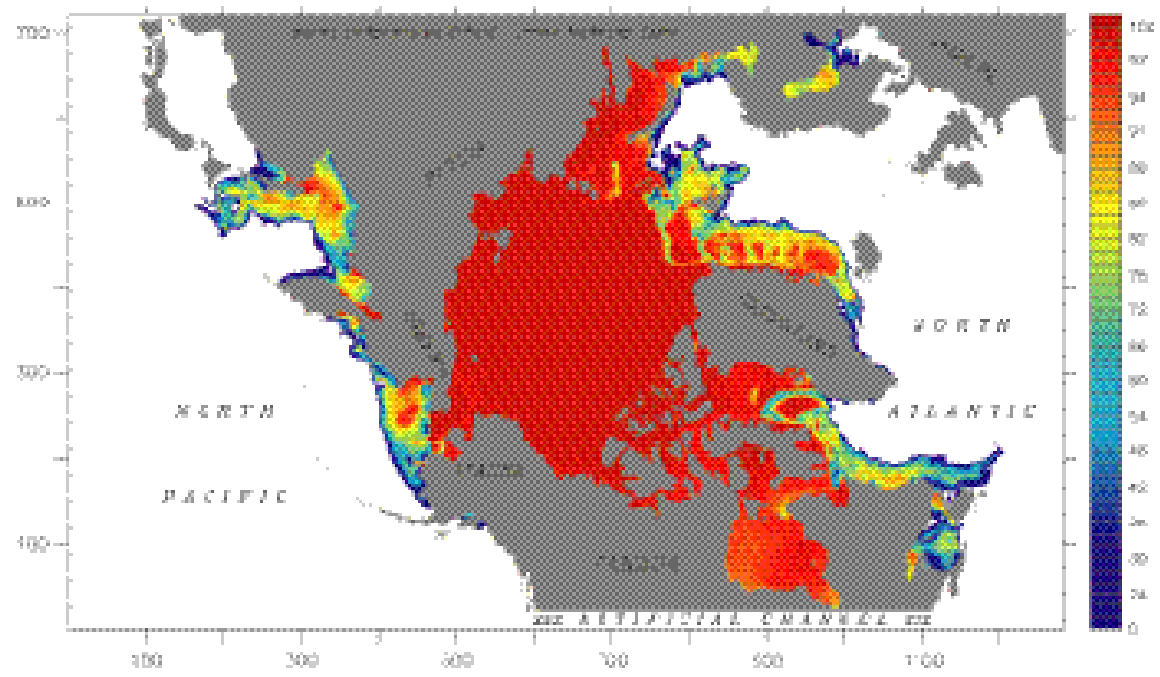

Fig. 4. A snapshot of sea ice concentration (\%) from the he 9-km PIPS 3.0 model from March of year 22 of the model spin-up. The full model domain is shown.

des a Lagrangian formulation for calculating multi-category ice thickness distribution, a snow layer, a non-linear profile of temperature and salinity (Bitz 2000) and a Coulombic yield curve for the viscous-plastic rheology (Hibler and Schulson, 2000).

Animations of ice concentration (Figure 4) and thickness fields (www.oc.nps.navy.mil/ pips3) show realistic details of the annual ice structure, including oriented leads in the Western Arctic, polynyas in the Bering and Chukchi seas, and seasonal ice-edge advancement/retreat in the marginal seas of the North Pacific and the North Atlantic. The position and structure of the ice edge position in those regions appears to be significantly influenced by the ocean dynamics and water mass properties (Zhang et., 1999).

In an effort to balance the net flow of water from the Pacific Ocean into the Arctic Ocean, a 500-m deep, 162-km wide channel was created through North America connecting the Atlantic Ocean to the Pacific Ocean (Figure 4). Along the channel, westward wind forcing is prescribed at the ocean surface but otherwise the flow through the channel and through Bering Strait is not prescribed. This approach results in a net mean transport of $0.65 \mathrm{~Sv}$ during the model spin-up (Figure 5) which is reasonably close to the observed mean flow through the Bering Strait of $0.83 \mathrm{~Sv}$.

Preliminary regional comparisons of eddy kinetic energy with our earlier 18-km version of the coupled ice-ocean model (Maslowski et al., 2000) reveal on average a tenfold increase in eddy kinetic energy in the 9-km model (Figure 6). Most importantly the large scale ocean circulation, which strongly influences the sea ice thickness 


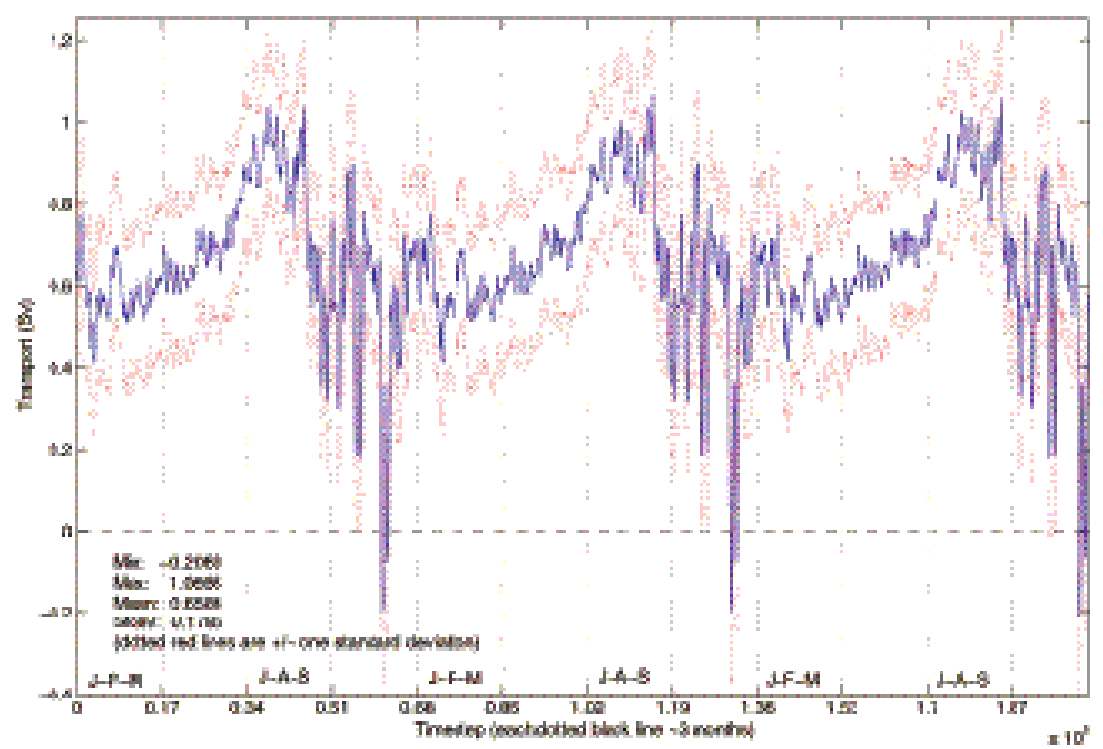

Fig. 5. The net volume transport $\left(1 \mathrm{~Sv}=10^{6} \mathrm{~m}^{3} \mathrm{~s}^{-1}\right)$ through the Bering Strait from the years 2426 of the model spin-up.

and concentration especially in marginal ice zones, is properly represented in this model. The narrow boundary currents associated with the continental margins of the deep central Arctic Ocean are only 100-150 km wide but they are believed to be the main sources of heat and salt advected northward from the North Atlantic. These predominantly barotropic flows are by definition strongly dependent on bathymetry (e.g. shelf slopes and submarine ridges), which provides another argument for using high resolution to resolve details of the bottom topography and boundary current flows.

One of the pathways of Atlantic Water transport into the Arctic Ocean includes the flow through the Barents Sea. We have analyzed monthly, seasonal and annual volume and property transports through the Barents Sea in order to evaluate model results in comparison with observations from this region. The calculated fluxes depend crucially on the inflow of heat and salt from the Norwegian Sea via the North Cape Current and on seasonal ice melt and growth in the Barents Sea. The modified Atlantic Water leaves the region primarily through the St. Anna Trough and it significantly affects Arctic Ocean water mass structure. The model realistically simulates known circulation and water mass characteristics as well as the seasonally dependent ice edge position in the Barents Sea. Results indicate an annual volume transport of 3.9 Sv and heat transport of 95TW into the Barents Sea, between Svalbard and Norway. Annual average volume and heat transport into the Arctic Ocean, between Franz Jo- 

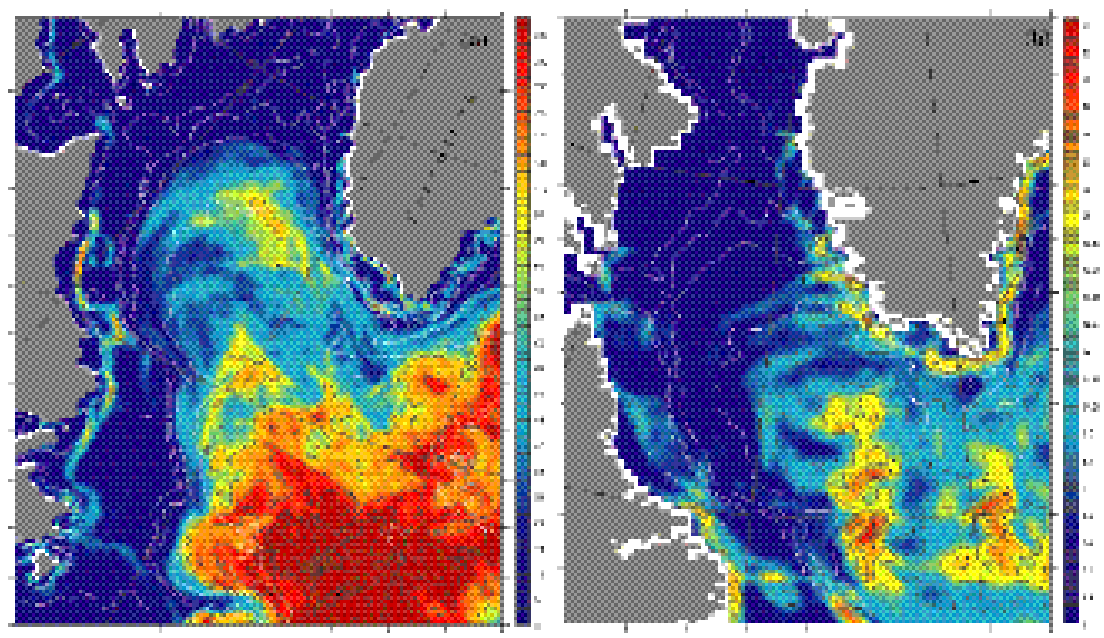

Fig. 6. The surface eddy kinetic energy $\left(\mathrm{cm}^{2} \mathrm{~s}^{-2}\right)$ in the Labrador Sea calculated from (a) the 9$\mathrm{km}$ model at depths $0-5 \mathrm{~m}$ for the year 13 of spin-up and (b) the $18-\mathrm{km}$ model at depths $0-20 \mathrm{~m}$ for the year 1997.

seph Land and Novaya Zemlya are 3.2 Sv and 16.6 TW, respectively. The magnitudes of the model transports agree well with observations. Continued integration using 1979-1999 daily varying interannual forcing will allow model-data comparison of interannual variability, including possible trends or regime shifts in response to large scale changes in the atmospheric weather patterns.

\section{Conclusions}

Results from two high resolution modeling efforts are presented to demonstrate the importance of high resolution in simulating the ocean and sea-ice circulation. Details of the $0.1^{\circ}, 40$-level global POP spin-up were provided along with initial results that showed the model to be realistically simulating surface frontal structures and mesoscale activity, both of which are very important to Navy prediction needs. In PIPS 3.0, mean volume and heat transports associated with the main pathways into the Arctic were found to be realistic compared with observations. Improvements to the sea ice model are likely to produce both more realistic ice configurations and seasonal-tointerannual variability in the multi-year ice cover. 


\section{Acknowledgements}

Funding was provided by the Office of Naval Research, the National Science Foundation, and the Department of Energy (CCPP program). The simulations were performed at the Army Research Laboratory, the Navy Oceanographic Office, the Arctic Region Supercomputing Center, and the Advanced Computer Laboratory at LANL. The drifter data was provided by the Atlantic Oceanographic and Meteorological Laboratory Drifting Buoy Data Assembly Center. Pam Posey and Steve Piacsek (both NRL) supplied the Navy winds and the initial condition, respectively. Collaborative work by Pierre Poulain and Jimmy Pelton on the drifter/model studies, and Doug Marble (all NPS) on the 9-km model are acknowledged.

\section{References}

1. Bitz, C.M., 2000: Documentation of a Lagrangian sea ice thickness distribution model with energy-conserving thermodynamics, APL-UW TM 8-00, 49 pp. University of Washington, Seattle, WA.

2. Bryan, F. O., R. D. Smith, M. E. Maltrud, and M. W. Hecht, 1998: Modeling the North Atlantic Circulation: From eddy permitting to eddy resolving. WOCE International Conference, Halifax, Nova Scotia.

3. Hibler, III, W. D., and E. M. Schulson, 2000: On modeling the anisotropic failure and flow of flawed sea ice, J. Geophys. Res., 105 (C7), 17,105-17,120.

4. Jakobsson, M., N. Z. Cherkis, J. Woodward, R. Macnab, and B. Coakley, 2000: New grid of Arctic bathymetry aids scientists and mapmakers, EOS Trans., Am. Geophys. Union, 81 (9).

5. Large, W. G., G. Danabasoglu, S. C. Doney, and J. C. Williams, 1997: Sensitivity to surface forcing and boundary layer parameterization. Rev. Geophys, 32, 363-404.

6. Maltrud, M. E., and R. D. Smith, A. J. Semtner, and R. C. Malone, 1998: Global eddyresolving ocean simulations driven by 1985-1995 atmospheric winds. J. Geophys. Res., 103, 30825-30853.

7. Maslowski, W., B. Newton, P. Schlosser, A. Semtner, and D. Martinson, 2000: Modeling recent climate variability in the Arctic Ocean, Geophys. Res. Lett., 27(22), 3743-3746.

8. McClean, J. L., P.-M. Poulain, J.W. Pelton, and M. E. Maltrud, 2001: Eulerian and Lagrangian statistics from surface drifters and two POP models in the North Atlantic, J. Phys. Oceanogr., submitted.

9. Smith, W.H.F., and D.T. Sandwell, 1997: Global sea floor topography from satellite altimetry and ship-depth soundings, Science, 277, 1957-1962.

10. Zhang, Y., W. Maslowski, and A. J. Semtner, 1999: Impact of mesoscale ocean currents on sea ice in high-resolution Arctic ice and ocean simulations, J. Geophys. Res., 104 (C8), 18,409-18429. 